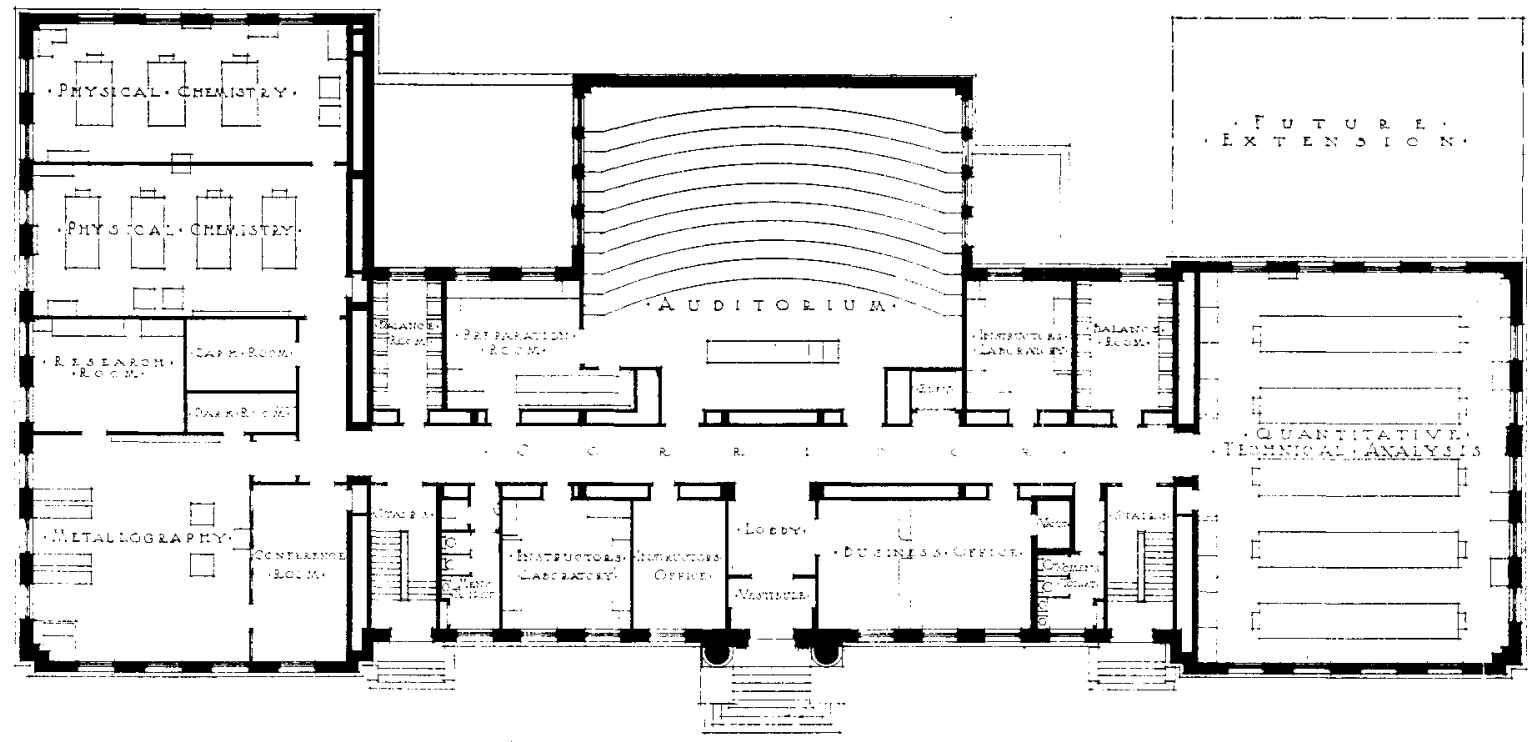

First Floor Plan, University of Cincinati

satisfaction. After all the bills were paid, a fund of \$1500 was left. To whom did this belong? It had been contributed for a special purpose, which had been accomplished. It was decided, after much consultation, that this fund should form a nucleus to help needy young people who wished to attend the Chemical Department, and who would "make good" in life if given an opportunity. It was decided that this money be loaned them, the principal and interest to be returned to the University when in later years they were enabled to do so, through the equipment they had received. Can a more important fund be established than this? Is the equipping of these young people to be good citizens and so situated as to care for the interests of their country, not an opportunity? I will take the liberty of reading the names of four of those who by their contributions have increased this fund to the sum of $\$ 2,000$. These are Dr. Ernst Twitchell, Dr. F. W. Weissmann, Mr. Robert Hochstetter, and the firm of Ault and Wiborg. May I not be permitted to predict that those who can help this fund in the city of Cincinnati will be surprised, fifty years from now, to know what this nest egg has accomplished?

As a closing thought, may I not be personal? Much do I appreciate the opportunity of speaking here to-day. To appear on the same platform with the learned men of this great University, including its President, to know that I am listened to by Dr. Herty, past president of the American Chemical Society, to be introduced by Judge Rufus B. Smith, of the Board of Trustees, and to speak to an audience made up of intellectual Cincinnati, is indeed an honor that anyone might well hold precious.

\section{THE SWING OF THE PENDULUM IN CHEMISTRY}

\section{By Chartes H. Herty}

It is a peculiar pleasure to be present on this occasion which marks the formal opening of the new Chemical Laboratory of the University of Cincinnati. Too often of late have we read of loss by fire of historic laboratories; too often have we heard the lament of laboratories overcrowded with students. Here brick and mortar have been promptly joined and a fine housing given to the splendid corps of instructors whose work and whose policies have given to this institution as high rank in chemistry as developed in America. Here, too, has been happily worked out a combination of devotion to the advancement of chemistry as a science and to the application of chemistry in the service of mankind.

The erection of this building gives heart to the hope that the pendulum which has swung so strongly during the past two and a half years towards the development of the chemical industries, is now about to begin an equally strong swing towards the betterment of conditions in our Universities-a betterment which should manifest itself in greater laboratory space and better equipment, in higher salaries for the teaching staff and in such increased number of instructors as will make possible more time for research. If the pendulum does not begin soon to swing strongly in this direction there is danger ahead.

\section{CONDITIONS UP TO IOI 4}

Up to the outbreak of the present great war the chemists of America had been working quietly but with zeal and effectiveness in university laboratories until we had reached the point where no longer was it considered necessary to go abroad to receive thorough and inspiring training in chemical research. This fact had not been widely advertised but it was evidenced by the constant increase in the proportion of young men receiving their higher training in the universities of this country, and by the constantly increasing prestige of the chemical journals. of America.

So, too, in the industries of America, chemists had been busily and successfully engaged in solving the many problems of those industries which, because of our resources and environment, were of primary importance. Corn, the great staple of the Middle West, had been converted into a host of useful substances, through the transforming agency of our chemists. Cottonseed, so long neglected in the southern states, had become the raw material of a great industry whose output now approaches in value that of the lint column which for many years had alone given value to the cotton crop. The advances in metallurgy furnished brilliant examples of skill, ingenuity and sound chemical development. Petroleum refining had made possible the tremendous development of the automobile and allied industries. The tanning of leather had been placed upon surer foundations. The great industries of the heavy chemicals, acids, alkalies, etc., received a development of such consummate skill and magnitude of output as to assure success in other lines. At Niagara Falls an electrochemical industry was founded which stands to-day the greatest of its kind in the world, the products of this group now constituting essential equipment of many industries throughout the nation, and assuring us a degree of national preparedness, whose importance no one can overestimate in the great war into which we are entering. These are only a few illustrations of the many-sided and successful efforts of the industrial chemists previous to the outbreak of the present war. 


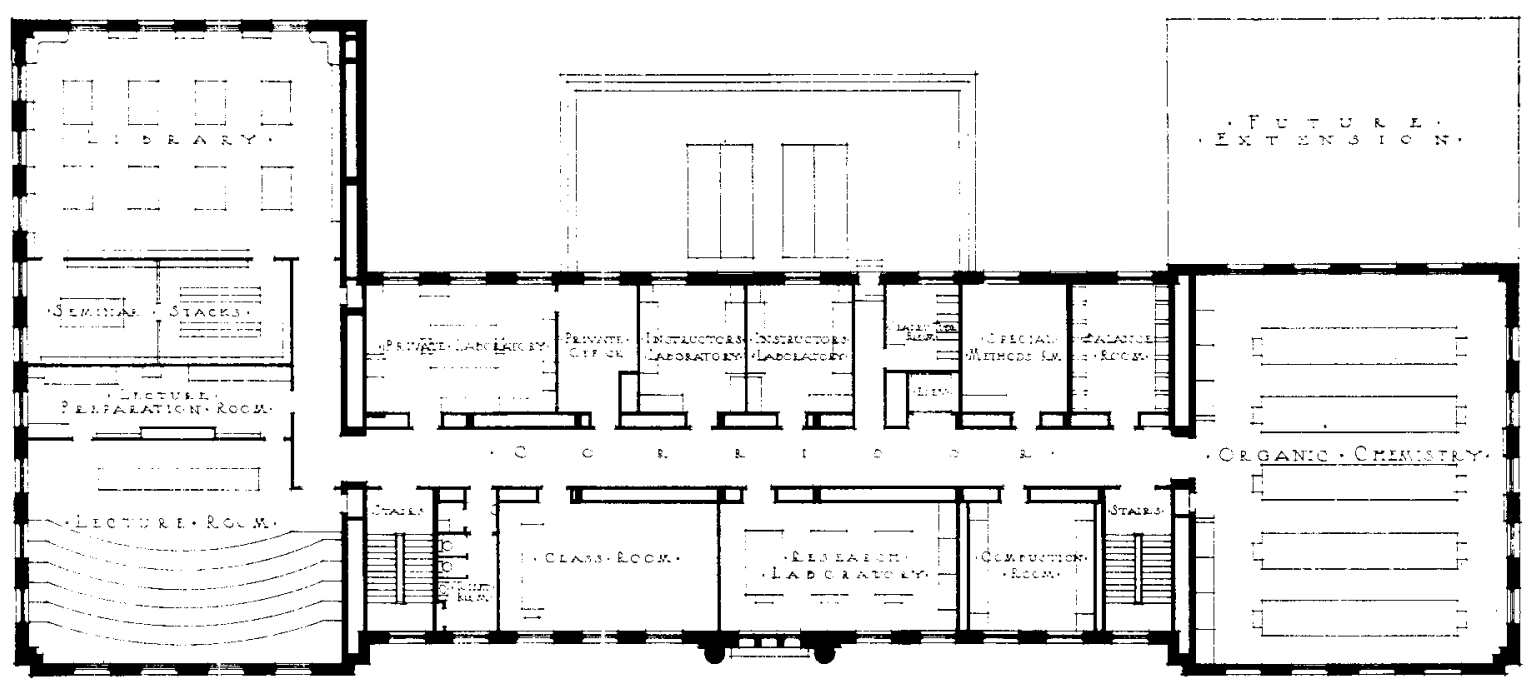

Second Floor Plan, University of Cincinnati

The work, had been done quietly, earnestly and without advertisement and the nation accepted the results with but scant credit to those who primarily were responsible for the splendid achievements. It was, therefore, perhaps natural that with the shortage in coal-tar chemicals made manifest through the blockade of German ports, the nation should suddenly have awakened to the importance of its chemists and in that condition which is so often characteristic of rousing from sound slumber petulantly exclaimed: "Why have not our chemists provided us with a dyestuff industry commensurate with our needs?" Some rough jolts were necessary to make clear the situation that chemists alone cannot always develop industries, that combination of capital with chemical skill is essential and that capital is not inclined to invest in industries whose fostering, through adequate tariff legislation, has not only been neglected but strongly opposed by our own consumers. The full wakening, however, was not long delayed and with fine spirit consumers, capitalists, and chemists joined hands, effecting the development of a domestic dyestuff industry which has amazed the world, and which on the morrow, in the annual Easter parades; will give abundant evidence of its life and vigor.

EXPANSION OF CHFMICAL INDUSTRIES SINCE T9I4

Along with developments in connection with industries using coal-tar products as raw materials, there has also been a great expansion in all other lines of chemical industries, which during the years 1915,1916 and the first three months of 1917 has called for a direct investment in these industries of $\$ 184,139,000$. Not even the greatest optimist could have foreseen such an enormous expansion of the strictly chemical industries in so brief a time. The successful use of this vast sum has aroused the admiration of our people and to-day the chemist occupies a new plane in American public esteem, a position rendered all the more secure by the universal recognition of the important rôle the chemist plays in modern warfare.

To meet the universal demand for thoroughly trained men the industries have drawn heavily on university ranks. Men long habituated to the lecture room and university laboratory have taken new positions in the ranks of the industries and with characteristic American adaptability have fully met the new responsibilities. If this drain on University staffs goes much further there is distinct danger ahead to both the universities and the industries. In the universities should always be found men of the highest possible type, whose researches will carry forward the science of chemistry which usually precedes discoveries fundamental to the fullest development of the chemical industries. Such men attract and hold within universities for graduate work the best class of the undergraduate body upon which the future of chemistry in America will largely depend.
INCREASE IN CHEMISTRY STUDENTS

Furthermore, the wide advertisement which chemical prowess and prestige have recently received has resulted in largely increased numbers in chemistry classes working in laboratories taxed to utmost capacity. In order to secure facts in this connection a questionnaire, that most dreaded of all documents which pass through our mails, was sent to the registrars of all American colleges and universities listed in the report of the United States Commissioner of Education for the year ending June 30,1916 . In the hope of receiving reasonable returns the amount of statistics requested was very limited. Information was asked for the institutional years $1914-15,1915-16$, and I $16-17$ as to the total number of students in chemistry, in chemical engineering, and in graduate courses in chemistry, and as to the amounts appropriated to chemistry departments (not including salaries) from funds other than fees paid by students.

Returns from this questionnaire have been slow in coming in and the information is far from complete. Nevertheless statistics have been received from one-third of our colleges and universities and fortunately these figures cover typical institutions, both the larger universities and smaller colleges being represented in approximately the same ratio as in the complete list of the Commissioner of Education.

The figures as to total students in chemistry are not suitable for use as misunderstandings arose as to whether the total number of individuals or the total enrollment of the classes had been requested. Nor are the figures as to appropriations to chemical departments suitable for specific use, as very few institutions answered this question. From those which did answer, however, it would seem that for the most part the chemistry departments of our colleges and universities subsist almost entirely, outside of the professors' salaries, on fees paid by the students. Appropriations from general university funds are in most cases negligible. It is to be regretted that a definite showing cannot be made in regard to this matter. To all who appreciate the unusual cost of material and equipment for research it must be plain that unless special appropriations are made from funds other than those received from students, the untrammeled prosecution of research must necessarily be hampered.

From this questionnaire, however, two reliable sets of figures have been received and these are exceedingly gratifying in view of the increased demand for trained chemists, both in the control work and in research in the chemical industries whose continued development and expansion are so important at this particular time. For the session 1915-16 the registration of students in chemical engineering was 37 per cent greater than during the session of $1914^{-15}$, while the increase of $1916-17$ 


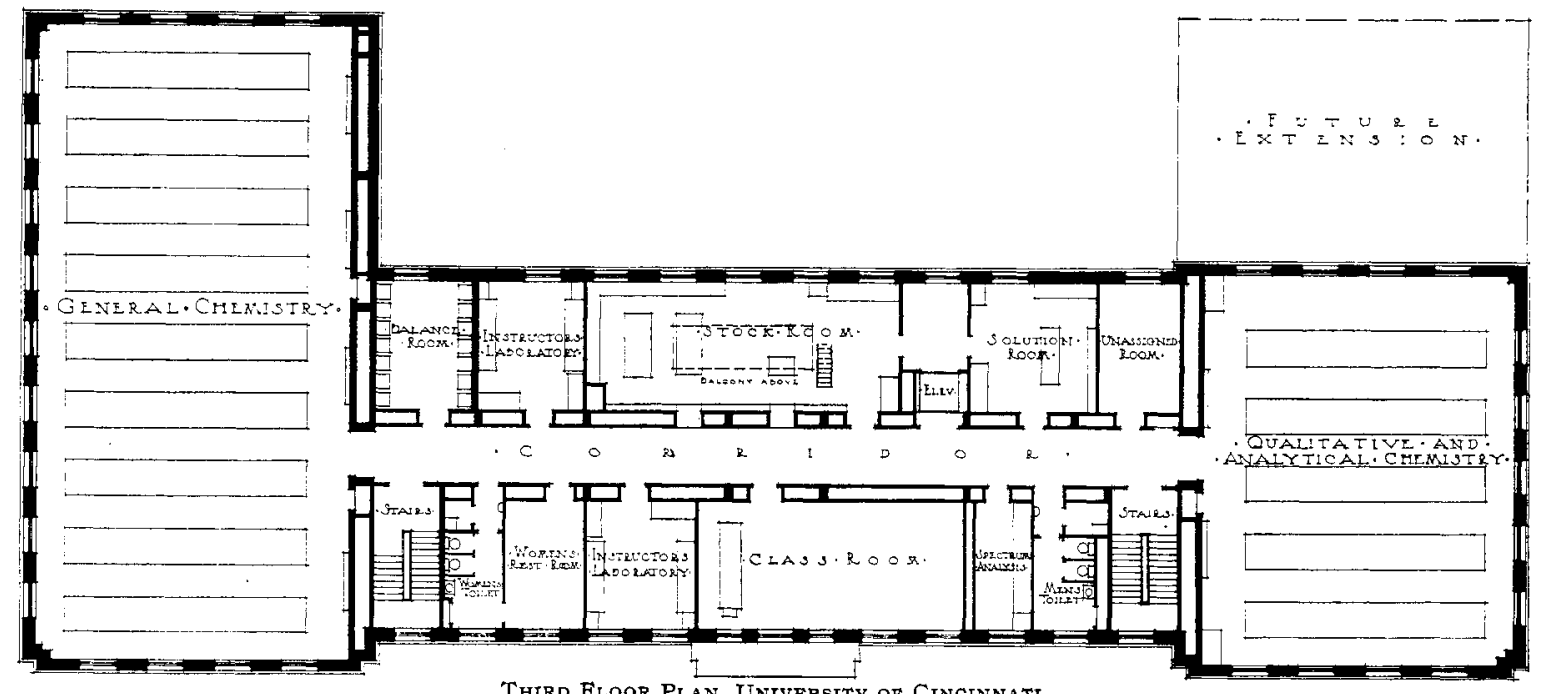

over I9I5-I6 was $2 \mathrm{I}$ per cent. The increase of the current session over 1914-15, which marked the outbreak of the war, is 65.7 per cent. When we consider the great need of chemical engineers this marked response on the part of students gives us a feeling of confidence for the future. Too often during the past two years has there been evidenced by those in charge of the erection of industrial plants an unfortunate lack of knowledge of chemistry from the engineering standpoint. Large sums of money have been lost through errors in plant design, resulting in some cases in the necessity of rebuilding. In many others the result has been inefficient operations which would have brought failure save for favorable contracts and the extraordinary prices resulting from almost famine in certain lines. Such plants cannot hope to exist when days of normal competition are again restored. It is greatly to be hoped that in those institutions training chemical engineers, more and more thought may be given to the important problem of acquainting students with the details of efficient plant design and construction, and especially that continued thought be given to the matter of coöperation between the universities and industries which will result in giving at least some plant experience to students during the days of their collegiate and university training. Interesting experiments are being made along several lines at a number of American institutions of learning. More such are needed, for in this way only, just as in the laboratory and plant, can the wisest solution of the problems be reached. It is unnecessary for me to urge this spirit here in this institution where already a definite policy has been marked out and where for years coöperative students have acquired valuable training which is to-day itself felt in many lines of chemical industry.

Another showing made by the questionnaire is one which has given a strong feeling of relief. During the past $2^{1 / 2}$ years there has been a tremendous demand for young men trained to the extent of an undergraduate course. For the services of such young men good salaries have been offered, as well as opportunities for advancement, and the privilege of taking part in the development of new organizations, which in itself is always a strong attraction for any young man of courage and spirit. It was feared, therefore, that this strong and attractive demand would be at the expense of the number of students in graduate work. If the results from the questionnaire are at all reliable we may comfort ourselves in the knowledge that from the figures received there was in $1915^{-16}$ an increase of graduate students of 37 per cent over r914-15, while during the current session the number has at least not decreased and will probably show a small increase over the preceding session. The importance of this situation cannot be overestimated. If we are to measure up to our responsibilities in the development of chem- istry the number of our graduate students must not diminish; nay, it should constantly increase no matter what personal sacrifices are involved in prolonged university residence, for through the work of this class of students the leaders of research will be enabled to carry on most successfully the advance in pure chemistry, while from the training thus received there will be developed minds capable of grappling with the problems of industries and of blazing out new paths of advance so characteristic of this nation. More than this, many lines of industry in this country are just beginning to awake to the value of chemical research in their organizations, so that we must supply the need not only for new industries but also for a great number of our older and more established industries in which the trained chemist, through systematic research, will work wonders hitherto undreamed of.

INCREASES IN SALARIES, NUMBER OF TEACHERS AND LABORATORY EQUIPMENT ESSENTIAL

In view of this increase in graduate students in chemistry, chemical engineering and the general courses in chemistry, and in further view of the draft made upon our university faculties by the chemical industries, it is high time influences should make themselves felt which will swing the pendulum, now so far swung to our chemical industries, back to the university side. This is important not only from the standpoint of the university but from the standpoint of the industries themselves, for it is from the universities that the industries draw their trained men, and only with the highest university development will we have more than a spasmodic expansion of the chemical industries. To what influence shall we look for this counterswing of the pendulum? The immediate answer is, to our university and college executives. Their influence has the greatest weight in the making up of the university budgets.

Along what lines can we justly ask their special consideration of the claims of chemistry? In the first place I would urge higher salaries for professors and their associates. While universities cannot hope to equal in their salary lists the offers made by industrial concerns, and while such an increase is unnecessary to persuade the man who loves to teach to remain in the university ranks, nevertheless it is but trite to remind of the constantly increasing cost of living which has characterized this war period. This means that where salaries have not been increased, they have been at least relatively decreased. Small wonder, therefore, is it, that men with responsibilities to others must take into account this decreased earning capacity? In the second place the increased number of students in chemistry signifies" clearly that unless teaching staffs are increased in numbers the character of the instruction given must suffer. There is a distinct limit to the number of men that can be success- 


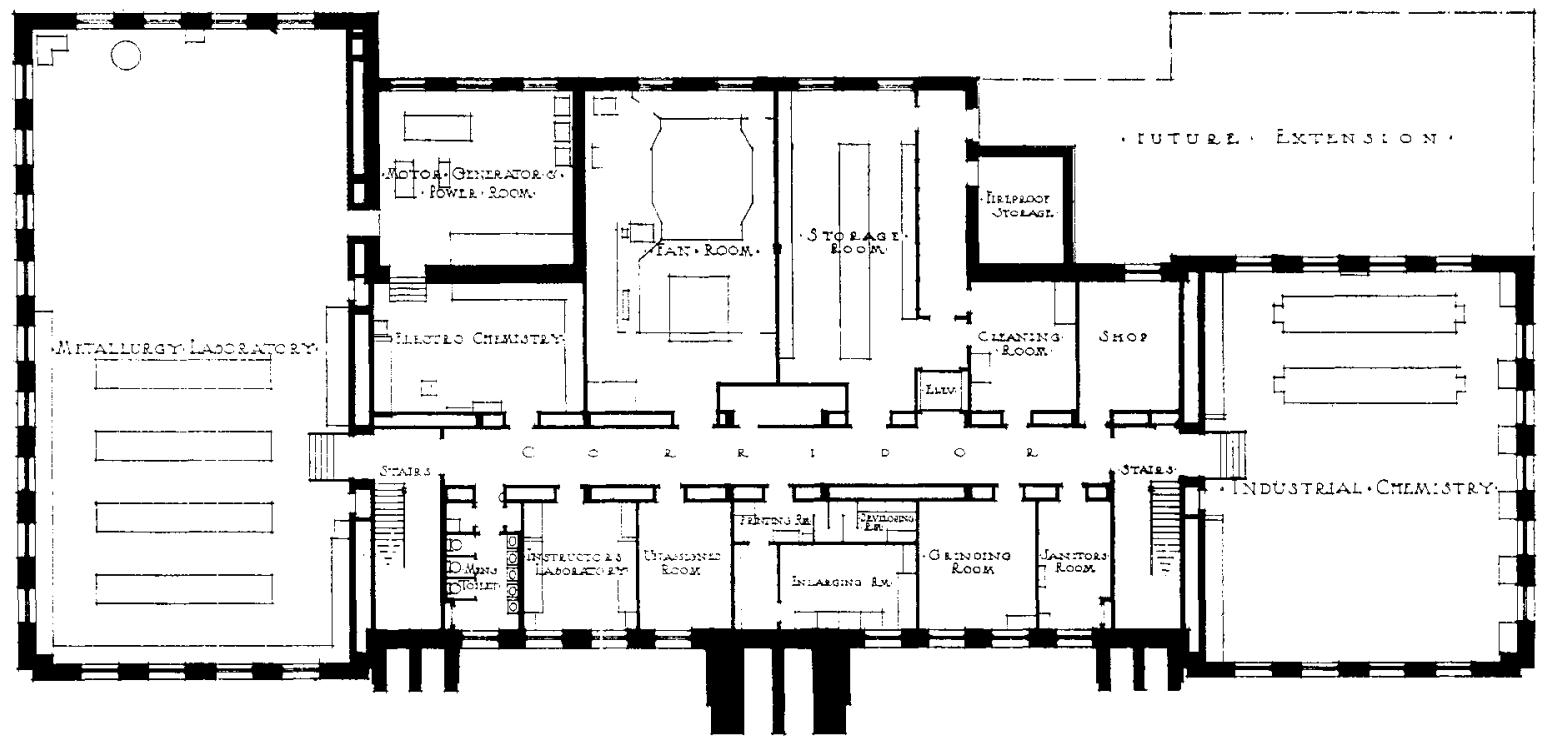

Basemint Plan, University of Cincinnati

fully taught by a capable instructor. The actual increase in students, therefore, is in itself sufficient argument for more instructors.

In the third place adequate laboratory space and equipment should be provided to meet fully all needs. This too has been well met here in this commodious building, but in many others such is not the case. Finally, all these cramping and restricting influences must make themselves felt in handicapping the efforts of the teaching force to prosecute research to the fullest extent. For such work freedom from financial cares is necessary; time for concentrated thought and continuous experimentation cannot be dispensed with and space and necessary equipment cannot be ignored if that work is to be carried out under the most favorable conditions.

When I think of the exodus of men from the universities to the industries the cure seems to be the same as is now beginning to prove so effective in the problem of urban and country life. It took many years before we fully grasped the thought that the solution of the problem of country life lay in the making of country life more attractive. So in our educational circles, if the universities are to hold their men, conditions which have now become in many cases so hard must be improved.

I recognize fully the tendency for each of us to think that our own work is of greatest importance and should be therefore particularly cared for, and under normal conditions I should hesitate to make this special plea for increased funds for chemistry in our universities. But with the signing by President Wilson of that memorable resolution of Congress which enters this nation as an active participant in the great war, this country enters upon a new era, in which every energy of the nation must be devoted to complete consummation of the purposes for which we entered this war and at the earliest possible moment. In this task it is recognized by all that the chemist plays an extremely important rôle. Cpon his inventiveness the issue may be largely determined.

\section{REAL TEST OF EFFICIENCY OF AMERICAN CHEMIST NOW BEGINNING}

A brilliant representative of the U. S. Navy, Admiral Fiske, I think, pointed out how often success in battle depends upon the unexpected use of some new discovery. Such a possibility will necessarily, through patriotic motives, lead our minds into many new channels, and the real test of the efficiency of the American chemist is now beginning. This test involves not only those men who are directly concerned with the manu- facture of munitions, with the development of new explosives, with the perfecting of alloys to meet new demands, with the conservation of food, with the testing of army and navy supplies and with the guarding of the health of the field forces, but it also involves, fundamentally, the work of instruction in our colleges and universities which should be maintained at its very highest possible standard in order that this country, which we all desire to serve even at the cost of our own lives, may be served most efficiently.

With such thoughts in mind I share with you that feeling of deep gratification which must fill your hearts as a result of the recognition of the needs of chemistry as expressed in the appropriation from the funds of the University of Cincinnati which has enabled the erection and equipment of this building.

\section{DESCRIPTION OF THE NEW CHEMICAL LABORATORY UNIVERSITY OF CINCINNATI}

Taken from Circular issued by the University of Cincinnati

The new chemical laboratory of the University of Cincinnati has a total frontage of $207 \mathrm{ft}$. and is, practically, four stories high, since the basement is mostly above ground, and is utilized for laboratory purposes. The west wing is $92 \mathrm{ft}$. long by 48 ft. 9 in. wide. The east wing, which is to be completed later, is $57 \mathrm{ft}$. long by $4^{8 \mathrm{ft} .9}$ in. wide. The cross bar connecting these two wings is $\mathrm{I}$ I $\mathrm{ft}$. long by $52 \mathrm{ft}$. wide. The total cost of the building was approximately $\$ 250,000$, including $\$ 25,000$ for special scientific equipment. It houses the Departments of Chemistry and Metallurgy. At the time of its occupation, in September I916, 520 students were enrolled in the various courses in chemistry and metallurgy.

\section{FIRST FLOOR}

The main auditorium for lecture purposes, which has a seating capacity of about 200 , is located on this floor opposite the entrance. Adjacent to it is the lecture preparation room for setting up lecture apparatus. In the west wing are two laboratories for work in physical chemistry, and a laboratory for advanced metallurgy, together with a research laboratory for the Department of Metallurgy. In connection with these laboratories there is a dark room for metallographic work and a constanttemperature room for work in physical chemistry. The other rooms on this floor are devoted to various purposes as follows: the business office in which the records of the department are kept on file and through which supplies are ordered; three in- 